\title{
Spontaneous Formation of AlInN Core-Shell Nanorod Arrays by Ultrahigh-Vacuum Magnetron Sputter Epitaxy
}

\author{
Ching-Lien Hsiao, Justinas Palisaitis, Junaid Muhammad, Ruei-San Chen, Per Persson, \\ Per Sandström, Per-Olof Holtz, Lars Hultman and Jens Birch
}

\section{Linköping University Post Print}

\begin{abstract}
N.B.: When citing this work, cite the original article.
\end{abstract}
Original Publication:

Ching-Lien Hsiao, Justinas Palisaitis, Junaid Muhammad, Ruei-San Chen, Per Persson, Per Sandström, Per-Olof Holtz, Lars Hultman and Jens Birch, Spontaneous Formation of AlInN Core-Shell Nanorod Arrays by Ultrahigh-Vacuum Magnetron Sputter Epitaxy, 2011, Applied Physics Express, (4), 115002.

http://dx.doi.org/10.1143/APEX.4.115002

Copyright: Japan Society of Applied Physics http://www.jsap.or.jp/

Postprint available at: Linköping University Electronic Press http://urn.kb.se/resolve?urn=urn:nbn:se:liu:diva-73161 


\section{Spontaneous Formation of AlInN Core-Shell Nanorod Arrays by Ultra- High-Vacuum Magnetron Sputter Epitaxy}

Ching-Lien Hsiao*, Justinas Palisaitis, Muhammad Junaid, Ruei-San Chen, Per O. A. Persson, Per Sandström, Per-Olof. Holtz, Lars Hultman, and Jens Birch Department of Physics, Chemistry and Biology, Linköping University, Linköping, Sweden

The spontaneous formation of ternary AlInN core-shell nanorod arrays with variable In concentration in the core has been realized onto $c$-plane sapphire substrates by ultra-high-vacuum magnetron sputter epitaxy with $\mathrm{Ti}_{0.21} \mathrm{Zr}_{0.79} \mathrm{~N}$ or $\mathrm{VN}$ seed layer assistance. Without the proper seed layer assistance, a continuous $\mathrm{Al}_{1-\mathrm{x}} \mathrm{In}_{\mathrm{x}} \mathrm{N}$ film was grown. The nanorods exhibit hexagonal cross sections with preferential growth along the $c$ axis. A core-shell rod structure with a higher In concentration in the core was observed by (scanning) transmission electron microscopy in combination with low-loss electron energy loss spectroscopy and energy dispersive X-ray spectroscopy. 5 K cathodoluminescence spectroscopy of $\mathrm{Al}_{0.86} \mathrm{In}_{0.14} \mathrm{~N}$ nanorods revealed band edge emission at $\sim 5.46 \mathrm{eV}$, which was accompanied by a strong defect-related emission at $\sim 3.38 \mathrm{eV}$.

*E-Mail address: $\underline{\text { hcl@ifm.liu.se }}$ 
The group III-nitride, including AlN, GaN, InN, and their alloys, nanomaterials have generated great interest in the past decade because high-performance semiconductor nanodevices are expected to be developed, such as high-sensitivity sensors, highresponsivity photodetectors, and high-brightness light-emitting devices. ${ }^{1-13)}$ To enhance the nanodevices' performance, single or multiple heterojunctions grown along the length of a nanorod or in its radial direction (core-shell structure) can be used..$^{8-13)}$ In particular, core-shell nanorods (nanowires) have large junction areas surrounding the rod surface, which can significantly enhance the quantum efficiency of the devices. Recently, spontaneous formation of ternary $\mathrm{InGaN}$ and $\mathrm{AlGaN}$ core-shell nanorods with variable In and $\mathrm{Ga}$ contents in the core, respectively, and intentional growth of $\mathrm{InGaN} / \mathrm{GaN}$ and AlGaN/GaN core-shell nanorods have been demonstrated. ${ }^{10-13)}$ However, the synthesis of ternary AlInN core-shell nanorods is still limited. The AlInN alloy, direct-bandgap semiconductor, was understood to exhibit key properties due to the broadest bandgap range, $0.7-6.2 \mathrm{eV}$, among the direct bandgap III-nitride semiconductors. ${ }^{14-18)}$ The development of vertically aligned $\mathrm{Al}_{1-\mathrm{x}} \mathrm{In}_{\mathrm{x}} \mathrm{N}$ nanorod arrays is an attractive route to fabricate broad-bandgap-range semiconductor nanoscale optoelectronics. Nonetheless, the bottom contact electrode is one of the problems for making devices when the nanomaterials are grown on nonconducting substrates. To resolve the problem, conducting seed layers grown on nonconducting substrates can be used. ${ }^{5,18)}$

In this study, $\mathrm{Al}_{1-\mathrm{x}} \mathrm{In}_{\mathrm{x}} \mathrm{N}$ core-shell nanorod arrays have been grown onto conducting $\mathrm{Ti}_{1-\mathrm{y}} \mathrm{Zr}_{\mathrm{y}} \mathrm{N}$ and $\mathrm{VN}$ transition metal nitride (TMN) seed layers on sapphire substrates. Here, $\mathrm{x}$ denotes the composition in the nanorod core. The composition of the $\mathrm{Al}_{1-\mathrm{x}} \mathrm{In}_{\mathrm{x}} \mathrm{N}$ was varied from $\mathrm{x} \sim 0.1$ to 0.3 and the rods were grown at a rate of $\sim 675 \mathrm{~nm} / \mathrm{h}$. 
Structure, composition, and optical properties were characterized by field-emission scanning electron microscopy (FE-SEM), X-ray diffraction (XRD), (scanning) transmission electron microscopy [(S)TEM], (valence) electron energy loss spectroscopy [(V)EELS)], energy dispersive X-ray spectroscopy (EDX), and low-temperature cathodoluminescence (CL) spectroscopy. The use of a TMN seed layer can pave the way for making the bottom electrodes on many nonconducting substrates and simplify device fabrication processes. Moreover, a high growth rate of the nanorods implies that a full structure of on-chip nanodevices may be fabricated within a few hours in the same chamber without breaking vacuum, which is an attractive scheme for large-scale production.

The sample growth was performed in an ultra-high-vacuum (UHV) magnetron sputter epitaxy (MSE) system. Details of the growth system can be found elsewhere. ${ }^{17,18)}$ The sapphire substrates were subsequently degreased with trichloroethylene, acetone, and isopropanol in ultrasonic baths for 5 min each and blown dry with pure nitrogen. Prior to the $\mathrm{Al}_{1-\mathrm{x}} \mathrm{In}_{\mathrm{x}} \mathrm{N}$ nanorod growth, the sapphire substrates were outgassed for $30 \mathrm{~min}$ at 1000 ${ }^{\circ} \mathrm{C}$. Then, a $\sim 30$-nm-thick $\mathrm{Ti}_{0.21} \mathrm{Zr}_{0.79} \mathrm{~N}$ or $\mathrm{VN}$ seed layer was deposited at $800{ }^{\circ} \mathrm{C}$ by sputtering from a titanium-zirconium alloy $\left(\mathrm{Ti}_{0.2} \mathrm{Zr}_{0.8}\right)$ or a vanadium target, respectively. Thereafter, the substrate temperature was lowered to $600-700{ }^{\circ} \mathrm{C}$ and the $\mathrm{Al}_{1-\mathrm{x}} \mathrm{In}_{\mathrm{x}} \mathrm{N}$ nanorods were grown by cosputtering from aluminum (99.999\%) and indium (99.999\%) targets. All the sputtering processes were carried out in a pure nitrogen (99.999999\%) atmosphere at a working pressure range of 5-10 mTorr, with a negative substrate potential of 15-30 V applied to the rotating substrate. Typical dc-magnetron powers provided for In and $\mathrm{Al}$ targets were varied in the ranges of $8-10$ and $240-350 \mathrm{~W}$, 
respectively, to control the $\mathrm{InN}$ mole fraction (x). The morphology and luminescence of the as-grown samples were characterized by a LEO-1550 FE-SEM, equipped with a liquid He-cooled Oxford Research Instrument CL system at temperatures ranging from 5 $\mathrm{K}$ to room temperature. The $\mathrm{CL}$ emission in the deep-UV to visible range was dispersed through a monochromator with a 1800 grooves/mm grating and a photomultiplier tube. Analyses of structural properties and compositional profiles were performed using $\theta / 2 \theta$ XRD and a FEI Tecnai G ${ }^{2}$ TF 20 UT 200 kV FEG microscope attached with EDX and EELS spectrometers, allowing for analytical mapping.

Figure 1 shows FESEM images of the $\mathrm{Al}_{1-\mathrm{x}} \operatorname{In}_{\mathrm{x}} \mathrm{N}$ nanorods. Well-separated $\mathrm{Al}_{1-}$ ${ }_{\mathrm{x}} \mathrm{In}_{\mathrm{x}} \mathrm{N}$ nanorods with hexagonal shape are demonstrated in the cross-sectional and topview SEM images, which are shown in Figs. 1(a) and 1(b), respectively. The rods have a uniform height of $\sim 2.7 \mu \mathrm{m}$ and diameter of $\sim 70 \mathrm{~nm}$ at the upper part of the rods after $4 \mathrm{~h}$ of growth, yielding a high growth rate of $\sim 675 \mathrm{~nm} / \mathrm{h}$ and an aspect ratio of $\sim 40$. The rod density is estimated to be $\sim 1.5 \times 10^{10} \mathrm{~cm}^{-2}$. The inset of Fig. 1(a) clearly shows that $\mathrm{Al}_{1-}$ ${ }_{x} \operatorname{In}_{x} \mathrm{~N}$ nanorods were nucleated on the flat $\mathrm{Ti}_{0.21} \mathrm{Zr}_{0.79} \mathrm{~N}$ seed layer, which was epitaxially grown on the sapphire substrate. When the $\mathrm{Al}_{1-\mathrm{x}} \mathrm{In}_{\mathrm{x}} \mathrm{N}$ was directly deposited on the sapphire substrate under identical growth conditions, an epitaxial film was formed. Hence, we conclude that the growth of nanorods depends on the proper seed layer assistance.

Figure 2 shows $\theta / 2 \theta$ XRD patterns from the $\mathrm{Al}_{1-\mathrm{x}} \mathrm{In}_{\mathrm{x}} \mathrm{N}$ nanorod samples with $\mathrm{In}$ concentrations of $0.10,0.14$, and 0.32 [curves (a), (b), and (c), respectively] as determined with Vegard's rule using bulk AIN and InN lattice parameters. ${ }^{19)}$ Except for $\mathrm{Al}_{1-\mathrm{x}} \mathrm{In}_{\mathrm{x}} \mathrm{N}$ 0002, $\mathrm{Al}_{2} \mathrm{O}_{3}$ 0006, VN 111, and $\mathrm{Ti}_{0.21} \mathrm{Zr}_{0.79} \mathrm{~N} 111$ peaks, no other $\mathrm{Al}_{1-\mathrm{x}} \mathrm{In}_{\mathrm{x}} \mathrm{N}$ crystal plane was found in a long-range scan (not shown here), indicating preferential 
0001-oriented growth along the rod-length direction. We found that both VN and $\mathrm{Ti}_{0.21} \mathrm{Zr}_{0.79} \mathrm{~N}$ seed layers can assist in the nanorod growth. Although the lattice mismatch between $\mathrm{Al}_{0.68} \mathrm{In}_{0.32} \mathrm{~N}$ and $\mathrm{Ti}_{0.21} \mathrm{Zr}_{0.79} \mathrm{~N}$ is only $1.5 \%$, the full width at half maximum (FWHM) of the $\mathrm{Al}_{0.68} \mathrm{In}_{0.32} \mathrm{~N}$ peak (overlapping with the $\mathrm{Ti}_{0.21} \mathrm{Zr}_{0.79} \mathrm{~N}$ ) is broader than the lower In content $\mathrm{Al}_{1-\mathrm{x}} \mathrm{In}_{\mathrm{x}} \mathrm{N}$ peaks. The peak broadening is related to a lower crystal quality for the higher In concentration $\mathrm{Al}_{1-\mathrm{x}} \mathrm{In}_{\mathrm{x}} \mathrm{N}$ alloys, which is to be expected due to the wide-range immiscibility $(0.1 \leq \mathrm{x} \leq 0.9){ }^{17,18)}$

The microstructure and compositional homogeneity of the $\mathrm{Al}_{1-\mathrm{x}} \mathrm{In}_{\mathrm{x}} \mathrm{N}$ nanorods were further analyzed by (S)TEM-EDX and EELS, by removing some rods from its substrate and placing them onto a freestanding carbon film. Figure 3(a) shows a masscontrast STEM micrograph of free nanorods from the $\mathrm{Al}_{0.86} \mathrm{In}_{0.14} \mathrm{~N}$ sample. The rods exhibit a core-shell structure. All the rods have a uniform core diameter of $\sim 30 \mathrm{~nm}$ and a slightly tapering rod top. No transition metal or transition metal nitride cluster is found at the rod top which excludes a catalyst-assisted vapor-liquid-solid (VLS) or VLS-like growth mechanism, ${ }^{20)}$ indicating a catalyst-free vapor-solid (VS) growth process initiated from self-induced nucleus islands. ${ }^{72,121)}$ A selected-area electron diffraction (SAED) pattern of a single rod with the electron beam direction perpendicular to the rod is shown in the inset of Fig. 3(a). The pattern shows grouped spots that can be indexed to a wurtzite structure with preferential $c$-axis orientation along the rod-length direction and a [2 $\overline{1} \overline{1} 0]$ zone axis. The result is in good agreement with the XRD observation. Figure 3(b) shows lattice-resolved images taken at the rod center and shell at positions marked with $\mathrm{A}$ and $\mathrm{B}$ in Fig. 3(a), respectively, which reveals a $\sim 23^{\circ}$ misorientation between the $c$ planes in the rod core and shell. The $c$ lattice parameters obtained by averaging 20 lattice 
constants are 5.09 and $5.00 \mathrm{~nm}$ at the core and shell, respectively. By converting the lattice constant to compositions using Vegard's rule, $x=\left(c_{A l_{1-x} I n_{x} N}-c_{A I N}\right) /\left(c_{I n N}-c_{A I N}\right)$, using the $c$ lattice constants of strain-free bulk AlN and $\mathrm{InN},{ }^{19)}$ the $\mathrm{InN}$ mole fractions are estimated to be $\sim 0.14$ and 0.03 at the rod core and shell, respectively, which confirms the core-shell nanorod structure. An elemental profile across the rod, obtained through an EDX nano-probe line scan in the TEM, is shown in Fig. 3(c), along with curves smoothed by averaging neighboring data points. It is clearly seen that the In concentration in the core is higher than that in the shell and vice versa for Al. To further confirm the radial concentration variation in the rods, a low-loss EELS line profile was acquired across the diameter of the rod. Figure 3(d) shows the peak energy position for the bulk plasmon $\left(E_{p}\right)$, which is highly dependent on the composition. ${ }^{16)}$ Here, the $\mathrm{E}_{\mathrm{p}}$ is smoothly varying with a dip at the center, indicating the core with the increased In content. The smoothly varying curve is understood from how $\mathrm{E}_{\mathrm{p}}$ is continuously affected by surface (of the rod) and interface (shell and core) plasmons. At the edge, the surface plasmons have a stronger influence on the $E_{p}$. Also, the $E_{p}$ at the center is derived from the projected $E_{p}$ of both shell and core, making direct compositional analysis difficult. These lines of evidence at a core-shell structure with different In concentrations reveal that phase separation occurred in the rod during growth. This may be associated with a spinodal decomposition ${ }^{18,22)}$ of the $\mathrm{Al}_{1-\mathrm{x}} \mathrm{In}_{\mathrm{x}} \mathrm{N}$ alloy due to the wide-range immiscibility and the low dissociation temperature of $\operatorname{InN}\left(550{ }^{\circ} \mathrm{C}\right) .{ }^{14,23)}$ Because the $\mathrm{Al}_{1-\mathrm{x}} \mathrm{In}_{\mathrm{x}} \mathrm{N}$ nanorods were grown in the range of $600-700{ }^{\circ} \mathrm{C}$, phase separation and In precipitation of $\mathrm{Al}_{1-\mathrm{x}} \mathrm{In}_{\mathrm{x}} \mathrm{N}$ are promoted by the higher In concentration. ${ }^{18)}$ 
Figure 4 shows a CL spectrum measured from the $\mathrm{Al}_{0.86} \mathrm{In}_{0.14} \mathrm{~N}$ core-shell nanorods at $5 \mathrm{~K}$. A broad peak with a strong intensity centered at $\sim 3.38 \mathrm{eV}$ and a weaker peak located at $\sim 5.46 \mathrm{eV}$ are observed. To clarify the weaker peak, the range of 4.2-6.5 $\mathrm{eV}$ is magnified by 30x and shown as an inset of Fig. 4. Except for the $5.46 \mathrm{eV}$ peak, no other peak, such as band edge emission of $\mathrm{AlN}$ at $6.2 \mathrm{eV},{ }^{24,25)}$ is found in the higher energy regime. The FWHM of the peak is $240 \mathrm{meV}$, which is narrower than the $3.38 \mathrm{eV}$ peak with an FWHM of $860 \mathrm{meV}$. The $5.46 \mathrm{eV}$ peak is in good agreement with the calculated band gap value for $\mathrm{x}=0.14(5.43 \mathrm{eV})$, assuming a linearly varied changing band gap of $\mathrm{Al}_{1-\mathrm{x}} \mathrm{In}_{\mathrm{x}} \mathrm{N}$ from $\mathrm{AlN}(6.2 \mathrm{eV})$ to $\mathrm{InN}(0.7 \mathrm{eV})$ without any observed band bowing. This was also observed in the $\mathrm{Al}_{1-\mathrm{x}} \mathrm{In}_{\mathrm{x}} \mathrm{N}$ thin film for $\mathrm{x}=0.20$ by Seppänen et al. 17) The broader $3.38 \mathrm{eV}$ peak is suggested to be the result of oxygen substituting for nitrogen in the lattice. This peak can vary with oxygen concentration from 3.3 to 4.0 $\mathrm{eV}^{24,25)}$

In summary, we have demonstrated the growth of $c$-axis-oriented standing $\mathrm{Al}_{1}$ ${ }_{\mathrm{x}} \mathrm{In}_{\mathrm{x}} \mathrm{N}(0.10 \leq \mathrm{x} \leq 0.32)$ core-shell nanorods, forming arrays on $c$-plane sapphire substrates by UHV MSE. The nanorods exhibited hexagonal cross sections. Seed layers of $\mathrm{VN}$ and $\mathrm{Ti}_{0.21} \mathrm{Zr}_{0.79} \mathrm{~N}$ play an important role in controlling the nanorod growth. Without a proper seed layer, $\mathrm{Al}_{1-\mathrm{x}} \mathrm{In}_{\mathrm{x}} \mathrm{N}$ films are grown. The absence of a foreign metal cluster on the rod top implies a catalyst-free VS growth process. A spontaneous formation of the core-shell structure with higher In concentration in the rod core indicates that a phase separation process occurred during the growth. Band edge emission located at $\sim 5.46 \mathrm{eV}$ in $\mathrm{Al}_{0.86} \mathrm{In}_{0.14} \mathrm{~N}$ was observed at $5 \mathrm{~K} \mathrm{CL}$ spectrum though accompanied by a strong defectrelated emission centered at $\sim 3.38 \mathrm{eV}$. 


\section{ACKNOWLEDGMENT}

The Swedish Strategic Foundation (SSF) is gratefully acknowledged for the financial support through the Nano-N and $\mathrm{MS}_{2} \mathrm{E}$ projects. 


\section{Reference}

1) S. Chattopadhyay, A. Ganguly, K. H. Chen, and L. C. Chen: Crit. Rev. Solid State 34 (2009) 224.

2) C. L. Hsiao, L. W. Tu, T. W. Chi, M. Chen, T. F. Young, C. T. Chia, and Y. M. Chang: Appl. Phys. Lett. 90 (2007) 043102.

3) C. Y. He, Q. A. Wu, X. Z. Wang, Y. L. Zhang, L. J. Yang, N. Liu, Y. Zhao, Y. N. Lu, and Z. Hu: ACS Nano 5 (2011) 1291.

4) C. Hahn, Z. Zhang. A. Fu, C. H. Wu, Y. J. Hwang, D. J. Gargas, and P. Yang: ACS Nano 5 (2011) 3970.

5) G. Z. Radnóczi, T. Seppänen, B. Pécz, L. Hultman, and J. Birch: Phys. Status Solidi A 202 (2005) R76.

6) R. S. Chen, S. W. Wang, Z. H. Lan, J. T. H. Tsai, C. T. Wu, L. C. Chen, K. H. Chen, Y. S. Huang, and C. C. Chen: Small 4 (2008) 925.

7) H. Kind, H. Yan, M. Law, B. Messer, and P. Yang: Adv. Mater. 14 (2002) 158.

8) J. Ristic, E. Calleja, A. Trampert, S. Fernández-Garrido, C. Rivera, U. Jahn, and K. H. Ploog: Phys. Rev. Lett. 94 (2005) 146102.

9) T. H. Hsueh, H. W. Huang, C. C. Kao, Y. H. Chang, M. C. Ou-Yang, H. C. Kuo, and S. C. Wang: Jpn. J. Appl. Phys. 44 (2005) 2661.

10) F. Qian, Y. Li, S. Gradečak, H. -G. Park, Y. Dong, Y. Ding, Z. L. Wang, and C. M. Lieber: Nat. Mater. 7 (2008) 701.

11) L. Baird, C. P. Ong, R. A. Cole, N. M. Haegel, A. A. Talin, Q. Li, and G. T. Wang: Appl. Phys. Lett. 98 (2011) 132104.

12) X. M. Cai, Y. H. Leung, K. Y. Cheung, K. H. Tam, A. B. Djurišič, M. H. Xie, H. Y. 
Chen, and S. Gwo: Nanotechnol. 17 (2006) 2330.

13) J. Su, M. Gherasimova, G. Cui, H. Tsukamoto, J. Han, T. Onuma, M. Kurimoto, S. F. Chichibu, C. Broadbridge, Y. He, and A. V. Nurmikko: Appl. Phys. Lett. 87 (2005) 183108.

14) J. Q. Wu: J. Appl. Phys. 106 (2009) 011101.

15) R. Butté, J. -F. Carlin, E. Feltin, M. Gonschorek, S. Nicolay, G. Christmann, D. Simeonov, A. Castiglia, J. Dorsaz, H. J. Buehlmann, S. Christopoulos, G. Baldassarri, H. von Högersthal, A. J. D. Grundy, M. Mosca, C. Pinquier, M. A. Py, and F. Demangeot: J. Phys. D: Appl. Phys. 40 (2007) 6328.

16) J. Palisaitis, C. L. Hsiao, M. Junaid, M. Xie, V. Darakchieva, J. Carlin, N. Grandjean, J. Birch, L. Hultman, and P. O. A. Persson: Phys. Status Solidi: Rapid Res. Lett. 5 (2011) 50 .

17) T. Seppänen, L. Hultman, and J. Birch: Appl. Phys. Lett. 89 (2006) 181928.

18) T. Seppänen, P. O. Å. Persson, L. Hultman J. Birch, and G. Z. Radnóczi: J. Appl. Phys. 97 (2005) 083503.

19) K. Kubota, Y. Kobayashi, and K. Fujimoto: J. Appl. Phys. 66 (1989) 2984.

20) B. A. Wacaser, K. A. Dick, J. Johansson, M. T. Borgström, K. Deppert, and L. Samuelson: Adv. Mater. 21 (2007) 153.

21) V. Consonni, M. Knelangen, L. Geelhaar, A. tramper, and H. Riechert: Phys. Rev. B 81 (2010) 085310.

22) M. Ferhat and F. Bechstedt: Phys. Rev. B 65 (2002) 075213.

23) C. L. Hsiao, L. W. Tu, M. Chen, Z. W. Jiang, N. W. Fan, Y. J. Tu, and K. R. Wang: Jpn. J. Appl. Phys. 44 (2005) L1076. 
24) S. C. Shi, C. F. Chen, S. Chattopadhyay, K. H. Chen, B. W. Ke, L. C. Chen, L. Trinkler, and B. Berzina: Appl. Phys. Lett. 89 (2006)163127.

25) R. A. Youngman and J. H. Harris: J. Am. Ceram. Soc. 73 (1990) 3238. 
Figure captions

FIG. 1. (a) Cross-sectional SEM image of the $\mathrm{Al}_{1-\mathrm{x}} \mathrm{In}_{\mathrm{x}} \mathrm{N}$ nanorods grown with a $\mathrm{Ti}_{0.79} \mathrm{Zr}_{0.21} \mathrm{~N}$ seed layer assistance. The inset shows the interface of $\mathrm{Al}_{1-\mathrm{x}} \mathrm{In}_{\mathrm{X}} \mathrm{N}$ nanorods $/ \mathrm{Ti}_{1-\mathrm{y}} \mathrm{Zr}_{\mathrm{y}} \mathrm{N}$ seed layer/sapphire. The scale shown in the inset is $60 \mathrm{~nm}$. (b) Corresponding top-view image of the $\mathrm{Al}_{1-\mathrm{x}} \mathrm{In}_{\mathrm{X}} \mathrm{N}$ nanorod arrays.

FIG. 2. $\theta / 2 \theta$ scan $\mathrm{XRD}$ patterns of $\mathrm{Al}_{1-\mathrm{x}} \mathrm{In}_{\mathrm{X}} \mathrm{N}$ nanorods grown on $\mathrm{VN}(111)$ and $\mathrm{Ti}_{0.21} \mathrm{Zr}_{0.79} \mathrm{~N}(111)$ seed layers with different In concentrations, $\mathrm{A}: \mathrm{x}=0.10 ; \mathrm{B}: \mathrm{x}=0.14 ; \mathrm{C}$ : $\mathrm{x}=0.32$. The $\mathrm{Al}_{0.68} \mathrm{In}_{0.32} \mathrm{~N}$ peak is overlapped with the $\mathrm{Ti}_{0.21} \mathrm{Zr}_{0.79} \mathrm{~N}$.

FIG. 3. (a) Mass/contrast STEM image of single free standing $A l_{0.86} \operatorname{In}_{0.14} \mathrm{~N}$ core-shell nanorods. Inset shows an SAED pattern of a selected nanorod that is almost perpendicular to other rods. (b) Lattice-resolved images of the selected rod taken at A: core and B: shell, as marked in Fig. 3(a). (c) EDX elemental line scan, with scanning direction as marked by the arrow in Fig. 3(a), plotted as electron beam scanning distance. (d) EELS line-scanned profile of the nanorod.

FIG. 4. Cathodoluminescence (CL) spectrum of the $\mathrm{Al}_{0.86} \operatorname{In}_{0.14} \mathrm{~N}$ core-shell nanorod array measured at $5 \mathrm{~K}$. The inset shows an intensity-enlarged CL spectrum in the region of $4-6 \mathrm{eV}$. 


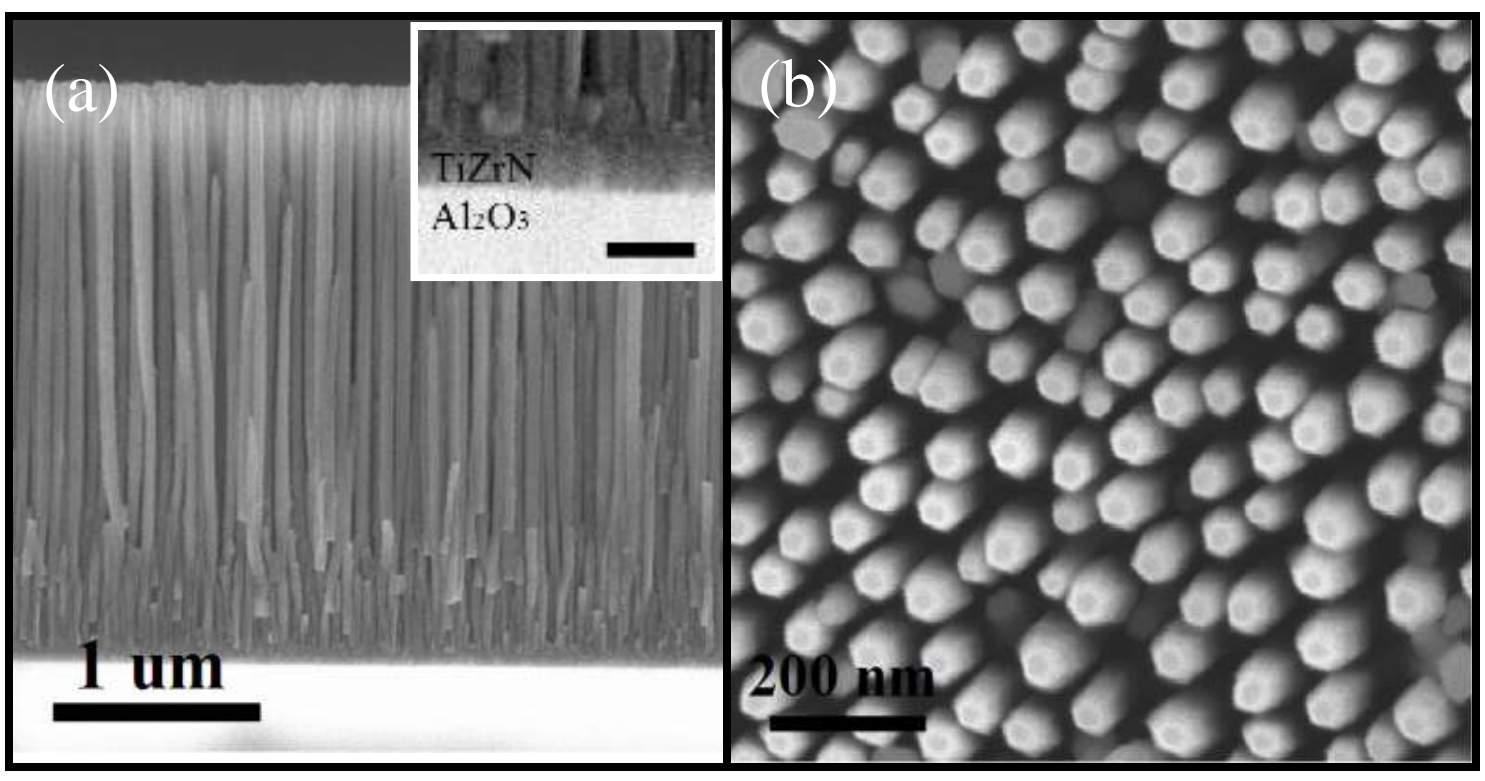

FIG. 1 


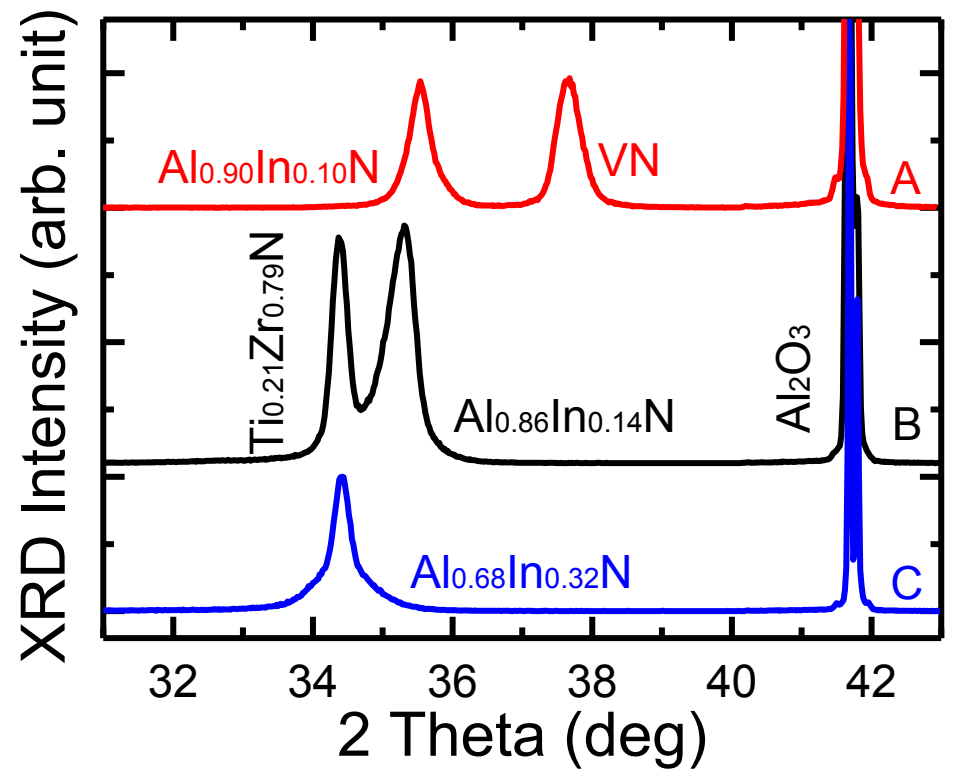

FIG. 2 


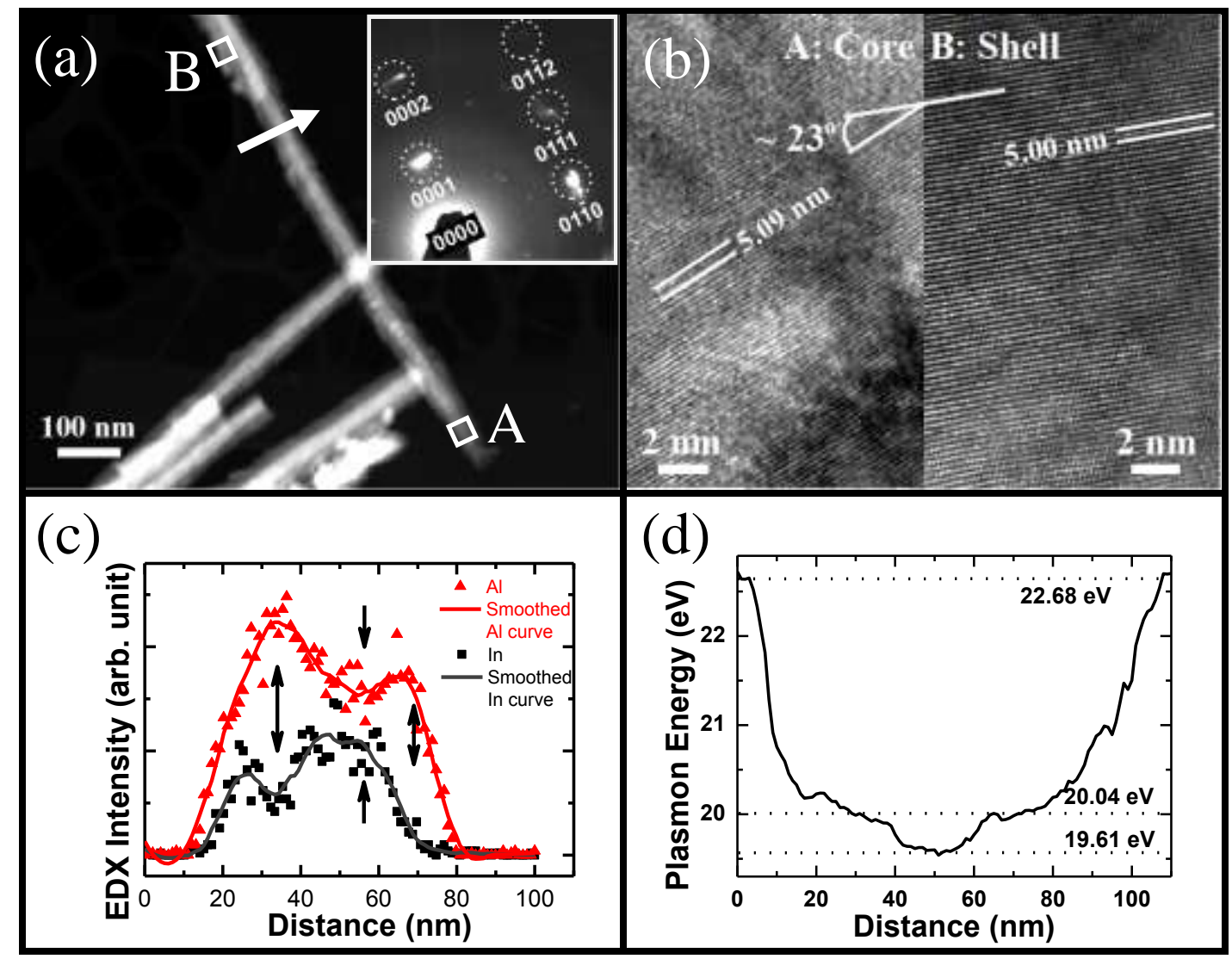

FIG. 3 


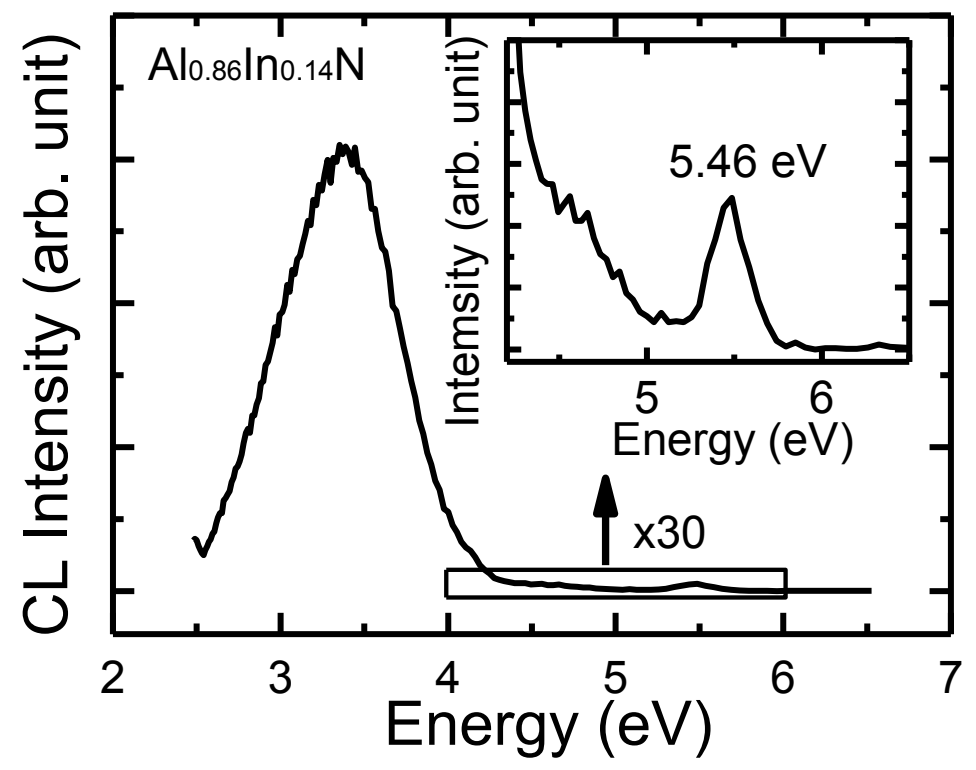

FIG. 4 